\title{
EVALUATION OF THE RESULTS FROM ARTHROSCOPIC SURGICAL TREATMENT FOR TRAUMATIC ANTERIOR SHOULDER INSTABILITY USING SUTURING OF THE LESION AT THE OPENED MARGIN OF THE GLENOID CAVITY
}

Alberto Naoki Miyazaki', Marcelo Fregoneze ${ }^{2}$, Pedro Doneux Santos ${ }^{3}$, Luciana Andrade da Silva ${ }^{3}$, Guilherme do Val Sella ${ }^{3}$, Clodoaldo Duarte ${ }^{4}$, Vinícius Botelho ${ }^{4}$, Sergio Luiz Checchia ${ }^{5}$

\begin{abstract}
Objective: To evaluate the clinical results from patients with traumatic anterior shoulder instability that was treated surgically through arthroscopic viewing, using bioabsorbable anchors and a technique for remove the cartilage of the anterior glenoid rim for repairing a Bankart lesion. Method: Between March 2006 and October 2008, 27 shoulders in 27 patients with a diagnosis of traumatic anterior shoulder instability were operated. The patients' mean age was 28 years and they had had between two and 25 previous episodes of dislocation. The patients were predominantly male $(24 ; 89 \%)$. The minimum length of follow-up was 24 months and the mean was 36 months. None of the patients had previously undergone surgery on the affected shoulder or had any significant bone lesion at the glenoid margin. The postoperative clinical assessment was done using the Rowe scale. To measure the
\end{abstract}

preoperative and postoperative joint range of motion, we used the method described by the American Academy of Orthopaedic Surgeons (AAOS). Results: According to the Rowe criteria, 25 patients $(93 \%)$ achieved excellent results and two (7\%) had poor results. None of the patients presented good or fair results. Twenty-three patients were satisfied with the results obtained (85\%), and returned to their activities without limitations, while four patients $(15 \%)$ had some degree of limitation. There was recurrence of instability in two patients (7\%). Conclusion: Treatment of traumatic anterior shoulder instability through arthroscopic viewing using a technique for remove the cartilage of the anterior glenoid rim for repairing a Bankart lesion provided excellent results for $93 \%$ of the patients operated.

Keywords - Shoulder Dislocation/therapy; Shoulder Dislocation/surgery; Arthroscopy

\section{INTRODUCTION}

Anterior post-traumatic shoulder instability is a disease related to injuries of the joint capsule, its ligaments and the glenoid labrum. For its treatment to be successful, the surgical approach has to be sufficiently flexible to deal with the variety of lesions encountered $^{(1)}$. Jakobsen et $\mathrm{al}^{(2)}$ found via arthroscopy that after the first episode of traumatic shoulder dis- location, the capsule or glenoid labrum injury rate is $93.5 \%$. From biomechanical analyses, Bigliani et $\mathrm{al}^{(3)}$ described stretching of the glenohumeral ligaments and joint capsule of the shoulder that occurs after repeated dislocations. These structural abnormalities of the capsule and ligaments lead to a recurrent pattern of dislocations, and not just Bankart lesions ${ }^{(4)}$.

For many years, open repair to correct Bankart

1 - Assistant Professor and Head of the Shoulder and Elbow Surgery Group, Department of Orthopedics and Traumatology, School of Medical Sciences, Santa Casa de São Paulo, São Paulo, SP, Brazil.

2 - Assistant Professor and Attending Physician in the Shoulder and Elbow Surgery Group, Department of Orthopedics and Traumatology, School of Medical Sciences, Santa Casa de São Paulo, São Paulo, SP, Brazil

3 - Attending Physician in the Shoulder and Elbow Surgery Group, Department of Orthopedics and Traumatology, School of Medical Sciences, Santa Casa de São Paulo, São Paulo, SP, Brazil.

4 - Trainee in the Shoulder and Elbow Surgery Group, Department of Orthopedics and Traumatology, School of Medical Sciences, Santa Casa de São Paulo, São Paulo, SP, Brazil.

5 - Adjunct Professor, Academic Consultant and Member of the Shoulder and Elbow Surgery Group, Department of Orthopedics and Traumatology, School of Medical Sciences, Santa Casa de São Paulo, São Paulo, SP, Brazil.

Work performed in the Department of Orthopedics and Traumatology, School of Medical Sciences, Santa Casa de São Paulo (DOT-FCMSCSP), Fernandinho Simonsen Wing, São Paulo, SP, Brazil. Director: Prof. Dr. Osmar Avanzi.

Correspondence: R. Dr. Cesário Mota Jr. 112, Vila Buarque, 01221-020 São Paulo, SP. E-mail: lucalu@terra.com.br / ombro@ombro.med.br

Work received for publication: May 12, 2011; accepted for publication: July 27, 2011.

The authors declare that there was no conflict of interest in conducting this work 
lesions was considered to be the technique that achieved the best and most durable clinical results ${ }^{(5)}$. However, these repairs are not free from complications, such as fractures of the anterior glenoid rim, violation of the tendon of the subscapularis muscle and prolonged duration of surgery ${ }^{(6)}$.

The advent of arthroscopy gave rise to improved recognition of anatomopathological lesions, thus providing better understanding of the etiology of anterior shoulder instability ${ }^{(7)}$. Johnson ${ }^{(8)}$ was the first to propose a technique for arthroscopic viewing, for use in treating anterior shoulder instability. This technique used metal staples and the recurrence rate was found to be $21 \%$. In 1988, Morgan and Bodenstab ${ }^{(9)}$ introduced a transglenoid suturing technique with arthroscopic viewing, for repairing Bankart lesions. In 1991, Wolf ${ }^{(10)}$ introduced a repair technique using anchors. Subsequent studies using this technique showed encouraging results, with instability recurrence rates ranging from 8 to $12 \%{ }^{(1,11-14)}$.

In a randomized prospective study, Moore reported similar failure rates from treating anterior shoulder instability using open and arthroscopic techniques ${ }^{(15)}$. In a recent meta-analysis, Hobby et $\mathrm{al}^{(16)}$ found similar results, with a mean failure rate of $8.9 \%$ and without any statistically significant difference in the failure rate in surgical techniques using anchors for lesion suturing, between open and arthroscopic routes.

In the traditional technique, suturing of the capsule and the glenoid labrum at the neck of the scapula is recommended. In recent studies, this has been described as a technique that provides worse results and should be avoided ${ }^{(17)}$. Alternatively, suturing on the cartilage of the anterior glenoid rim has been recommended $^{(10)}$ (Figure 1), which in our view adds difficulty to healing, since there is no open bone surface for contact with the capsule-ligament structures. Burkhart et $\mathrm{al}^{(18)}$ described a repair technique for these lesions in which 2 to $3 \mathrm{~mm}$ of the anterior glenoid rim was prepared using a curette or shaver blade to remove the cartilage, thus providing enough open surface for good healing (Figures 2 and 3 ).

The present study had the aim of evaluating the clinical results among patients with anterior shoulder instability that was treated surgically by means of arthroscopic viewing, using bioabsorbable anchors, in accordance with the technique described by Burkhart for repairing Bankart lesions ${ }^{(18)}$

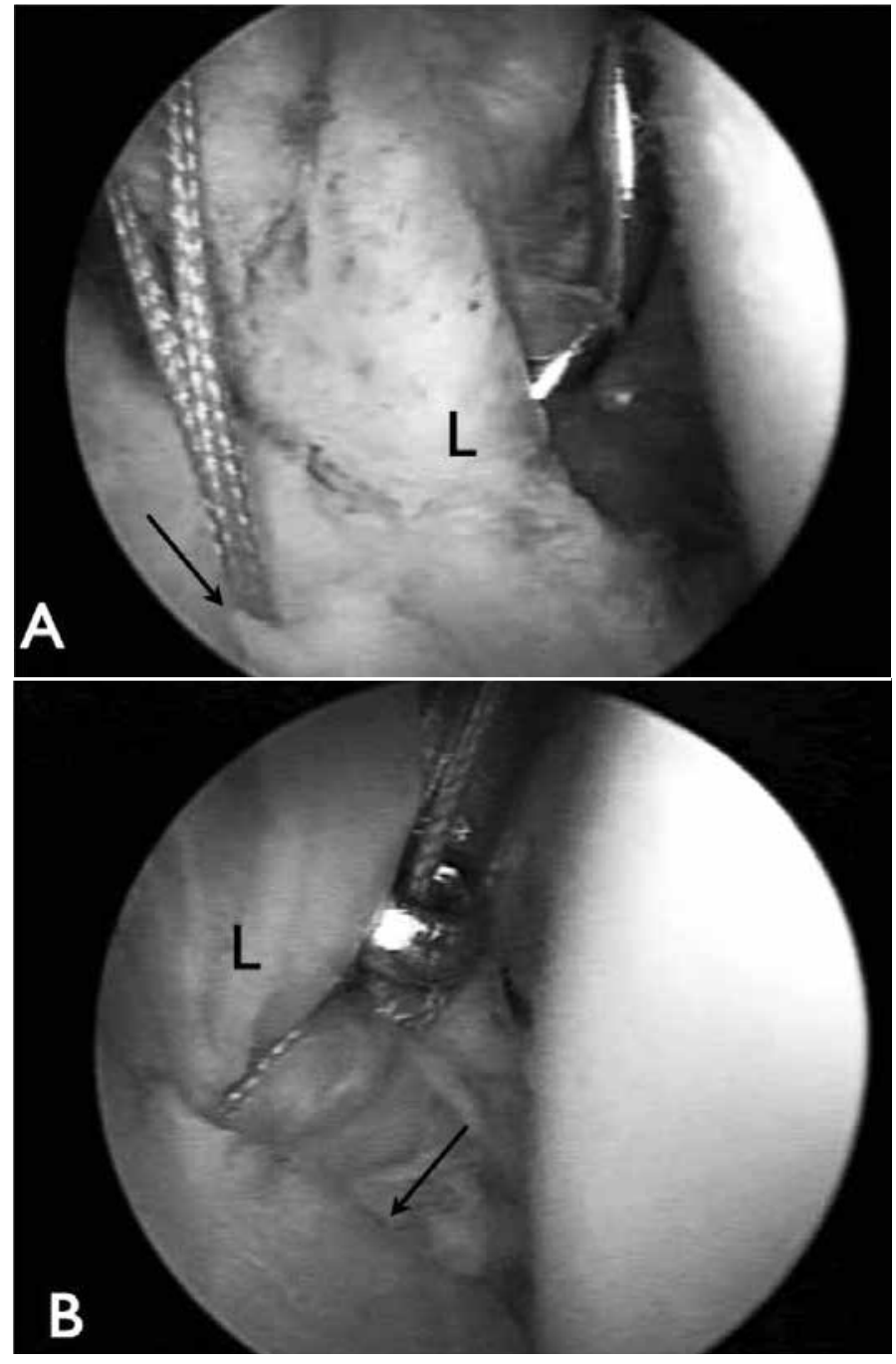

Figure 1 - View through the posterior portal of the right shoulder in deckchair position. $L-$ Glenoid labrum $A$ ) anchor fixed in the cartilaginous rim of the glenoid cavity (arrow). B) Bankart lesion repaired over the glenoid cartilage (arrow)

\section{MATERIALS AND METHODS}

Between March 2006 and October 2008, the Shoulder and Elbow Group of the Department of Orthopedics and Traumatology of the School of Medical Sciences of Santa Casa de São Paulo performed operations on 27 shoulders of 27 patients with a diagnosis of traumatic anterior shoulder instability.

Among these 27 patients evaluated, 24 (89\%) were male and three $(11 \%)$ were female. Their ages ranged from 17 to 49 years, with a mean of 28 years. The dominant side was affected in 21 patients $(78 \%)$. The time that elapsed between the first episode of dislocation and the surgical operation ranged from one to 360 months, with a mean of 67 months. The number of previous dislocations ranged from two to 25 episodes, with a mean of seven episodes. The length of the 


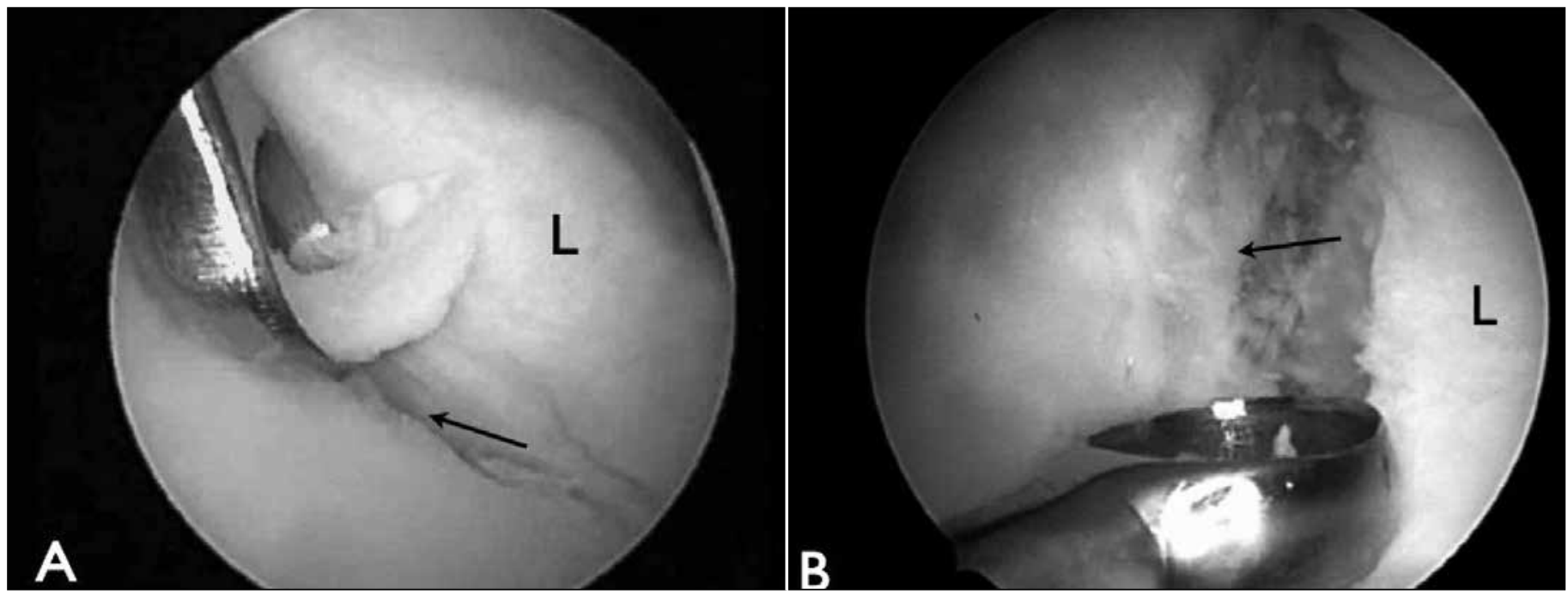

Figure 2 - Opening of the anterior joint margin of the glenoid cavity (glenoid rim) using a curette. L - Glenoid labrum. A) Opened joint margin viewed through the posterior portal (arrow). B) Opened joint margin viewed through the anterosuperior portal (arrow).

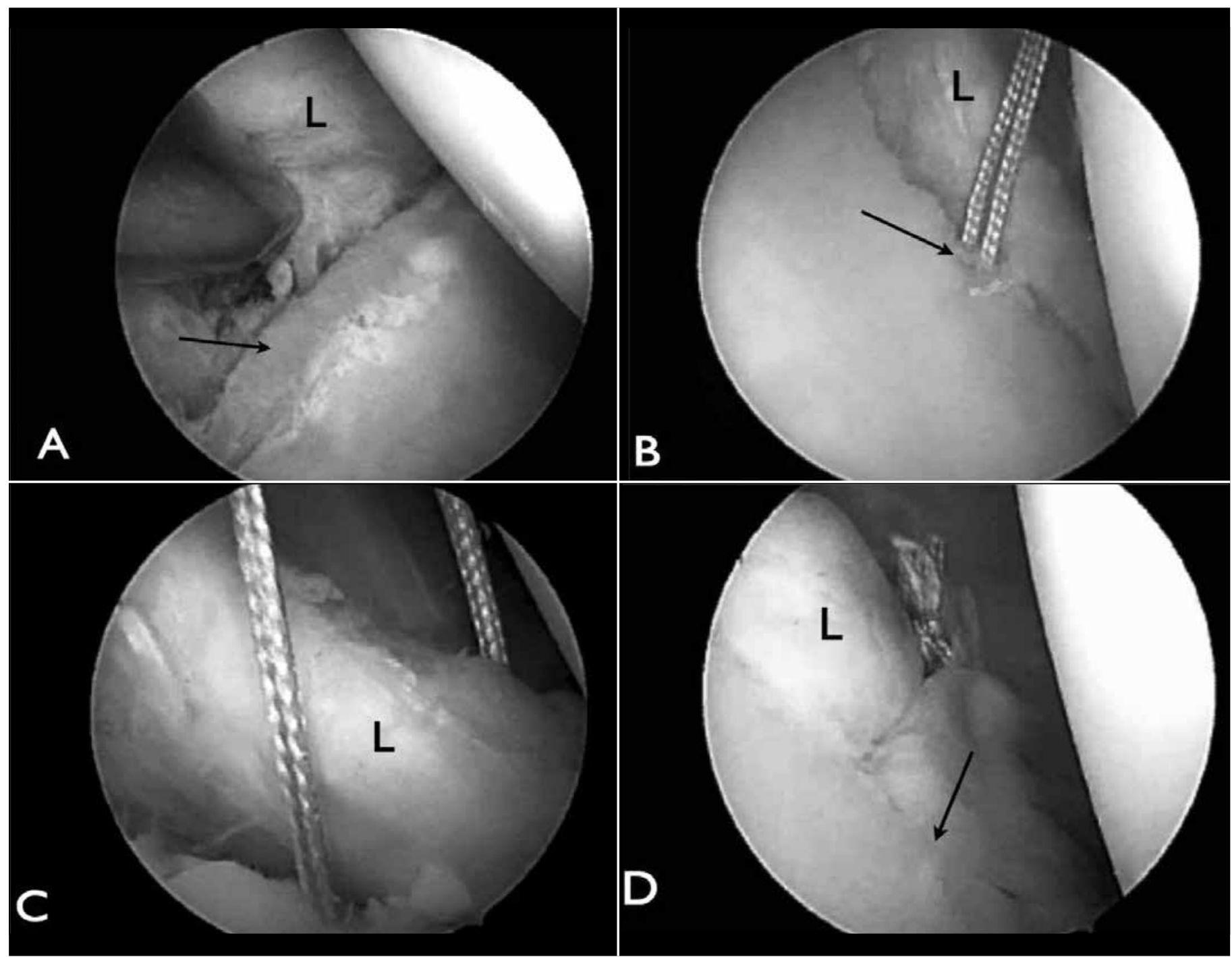

Figure 3 - After the joint margin had been opened, the Bankart lesion was fixed. L - Glenoid labrum. A) Opened joint margin viewed through the anterosuperior portal (arrow). B) Anchor fixed within the opened joint margin, viewed through the posterior portal (arrow). C) Anchor thread passing through the capsule-ligament tissue, viewed through the posterior portal (arrow). D) Repair of the Bankart lesion on the opened joint margin, viewed through the posterior portal (arrow). 
postoperative follow-up ranged from 24 to 51 months, with a mean of 36 months. Eighteen patients (69\%) were regularly practicing some type of physical activity.

We established the following as inclusion criteria: at least two episodes of traumatic anterior dislocation of the shoulder; at least 24 months of postoperative follow-up; and a surgical procedure performed under arthroscopic viewing, using the technique described previously. The exclusion criteria were: instability of non-traumatic etiology, uncontrolled epilepsy, follow-up for less than two years, previous surgery on the shoulder evaluated, bone lesion on the anterior glenoid rim greater than $20 \%$ and signs of capsule-ligament laxity.

All the patients presented signs of anterior apprehension with the shoulder at 90 degrees of abduction and external rotation in the preoperative clinical examination. Imaging examinations (radiographs, magnetic resonance or magnetic arthroresonance) were performed to view the Bankart lesion and evaluate any significant bone deficiency at the anterior glenoid rim, which was not shown in any case.

The surgical procedure with arthroscopic viewing was performed by means of regional blockade and general anesthesia, with the patient in lateral decubitus, under traction, or in the deckchair position, depending on whether any posterior lesion of the glenoid labrum was suspected, with a need for repair. An inventory of the joint cavity was made in order to identify the anteroinferior labral lesion and diagnose any other associated lesion. Such lesions were found in 11 of our patients: two posterior capsule-ligament lesions, one intra-articular free body, six SLAP lesions (four type II, one type III and one type V), one enchondroma of the humeral head and one joint fracture at the anterior glenoid rim with a small bone fragment (Table 1). Deinsertion of the labrum at the anterior glenoid rim was completed with the aim of facilitating its mobilization. Then, 2 to $3 \mathrm{~mm}$ of the anterior glenoid rim was opened using a curette or shaver blade to remove the cartilage, for subsequent suturing of the lesion (Figure 4). Fixation of the labrum-ligament complex of the shoulder joint was achieved using two to five bioabsorbable anchors with non-absorbable thread (mean of three anchors). Other procedures were performed in association with repairing the Bankart lesion, including the following: capsule plication (three cases, $11 \%$ ), repair of a posterior labrum-ligament lesion (two cases, 8\%), removal of a intra-articular free body (one case, 3\%), repair of SLAP lesions (six cases, 22\%), closure of the rotator gap ( six cases, 22\%) and tenotomy with tenodesis of the long head of the biceps (one case, 3\%) (Table 2).

After the operation, the patients used a sling for six weeks, with pendular movements and passive external rotation of the arm as far as neutral. After this time, active movement was allowed, and then, three months after the operation, muscle strengthening exercises

Table 1 - Lesions associated with the Bankart lesion.

\begin{tabular}{c|c}
\hline Intraoperative findings & Cases \\
\hline Posterior capsule-ligament lesion & 2 \\
\hline Intra-articular free body & 1 \\
\hline SLAP lesion & 6 \\
\hline Enchondroma of the humeral head & 1 \\
\hline Fracturing of the anteroinferior glenoid rim & 1 \\
\hline Total & 11 \\
\hline
\end{tabular}

Source: Medical files of Irmandade Santa Casa de Misericórdia de São Paulo. Legend: SLAP lesion - lesion of the superior labrum from anterior to posterior.

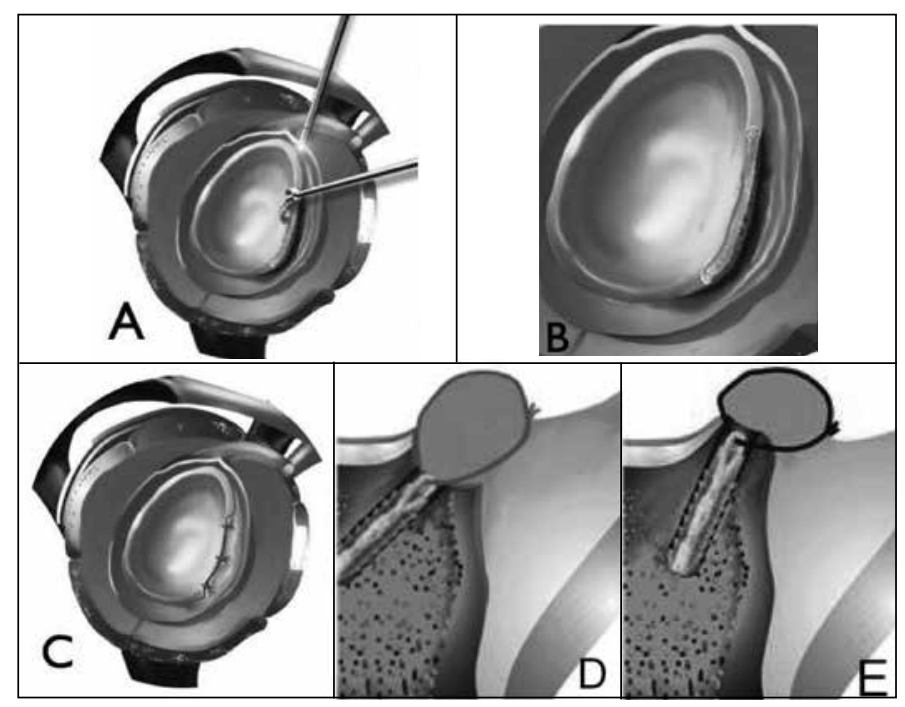

Figure 4 - Preparation of the bone bed and capsule-ligament reinsertion in the anterior glenoid rim: $(A)$ Opening of the anterior glenoid rim. (B) Opened anterior joint margin. (C) Bankart lesion repair. (D) Axial view after repairing of the Bankart lesion, with preparation of the bone bed. (E) Without preparation of the bone bed.

Table 2 - Procedures associated with Bankart lesion repairs.

\begin{tabular}{c|c}
\hline Procedures & Cases \\
\hline Capsule plication & 3 \\
\hline Repair of posterior capsule-ligament lesion & 2 \\
\hline Removal of intra-articular free body & 1 \\
\hline Repair of SLAP lesion & 6 \\
\hline Closure of rotator gap & 6 \\
\hline Tenotomy and tenodesis of the long head of the biceps & 1 \\
\hline Total & 19 \\
\hline
\end{tabular}

Source: Medical files of Irmandade Santa Casa de Misericórdia de São Paulo. Legend: SLAP lesion - lesion of the superior labrum from anterior to posterior. 
were started. The postoperative clinical assessment was done using the Rowe scale ${ }^{(5)}$. To measure the degree of preoperative and postoperative range of motion, we used the method described by the American Academy of Orthopaedic Surgeons (AAOS) ${ }^{(19)}$.

To calculate confidence intervals and perform hypothesis tests for proportions, approximations for normal distribution were not used, since the samples were very small and such approximations might not have been valid. Thus, the calculations used likelihood estimates. The significance level used was 0.05 , and therefore hypotheses in which the descriptive level (P-value) was less than 0.05 were rejected.

\section{RESULTS}

With a minimum postoperative follow-up of 24 months and a maximum of 51 months (mean of 36 months), following the Rowe criteria, the mean presented was 95 points (50-100). Twenty-five patients $(93 \%)$ had an excellent result and two (7\%) had a poor result; none of the patients presented good or fair results (Table 3 ).

The improvement in range of motion in relation to the preoperative period was seven degrees of elevation, 10 degrees of lateral rotation and one vertebral level of medial rotation. The postoperative means for mobility were 158 degrees of elevation (120-170 degrees), 66 degrees of lateral rotation (30-80 degrees) and T8 of medial rotation (T5-T12). Twenty-three patients were satisfied with the result obtained $(85 \%)$ and returned to their activities without limitations, while four patients (15\%) presented some degree of limitation.

Two patients presented recurrence of the instability (cases 17 and 22): one after sports trauma and the other, who was a professional Greco-Roman wrestler, during a competition 24 months after the operation. Two patients continued to complain of shoulder pain (cases 2 and 21): one with occurrences during intense physical exercise and the other while at rest, with limitations on mobility.

Table 3 - Patients operated using the technique of opening the anterior glenoid rim.

\begin{tabular}{|c|c|c|c|c|c|c|c|c|}
\hline Case & Sex & Age & Episodes & Preop mob & Apprehension & Postop mob & Rowe & Follow-up (months) \\
\hline 1 & $\mathrm{M}$ & 28 & 10 & 150/60/T5 & $S$ & 140/30/T8 & 100 & 51 \\
\hline 2 & $M$ & 20 & 3 & 150/60/T7 & $S$ & 160/60/T8 & 80 & 50 \\
\hline 3 & $M$ & 33 & 10 & 140/60/T10 & $S$ & $150 / 60 / T 8$ & 100 & 46 \\
\hline 4 & $M$ & 28 & 2 & $140 / 45 / \mathrm{T5}$ & $S$ & 140/60/T8 & 95 & 44 \\
\hline 5 & $M$ & 24 & 20 & 150/60/T7 & $S$ & $160 / 75 /$ T8 & 100 & 44 \\
\hline 6 & $M$ & 32 & 2 & 160/70/T8 & $S$ & $160 / 75 / \mathrm{T} 7$ & 100 & 38 \\
\hline 7 & $M$ & 36 & 25 & $150 / 70 / \mathrm{T} 5$ & $S$ & $170 / 50 / \mathrm{T} 6$ & 100 & 40 \\
\hline 8 & $\mathrm{M}$ & 23 & 5 & 170/60/T5 & $S$ & 170/75/T7 & 100 & 40 \\
\hline 9 & $\mathrm{M}$ & 22 & 10 & 160/70/T12 & $S$ & 160/80/T6 & 100 & 40 \\
\hline 10 & $\mathrm{M}$ & 24 & 4 & 170/60/T5 & $S$ & $170 / 80 / \mathrm{T} 6$ & 100 & 38 \\
\hline 11 & $\mathrm{M}$ & 26 & 3 & 150/70/T10 & $S$ & 160/70/T8 & 100 & 37 \\
\hline 12 & $\mathrm{M}$ & 31 & 3 & 150/60/T10 & $S$ & 170/70/T8 & 100 & 37 \\
\hline 13 & $M$ & 18 & 2 & 150/60/T3 & $S$ & 160/70/T5 & 100 & 24 \\
\hline 14 & $M$ & 28 & 12 & 170/60/T5 & $S$ & 160/70/T5 & 100 & 28 \\
\hline 15 & $M$ & 38 & 8 & 170/60/T5 & $S$ & 160/80/T6 & 100 & 28 \\
\hline 16 & $M$ & 17 & 2 & $150 / 60 /$ T5 & $S$ & 150/60/T8 & 100 & 27 \\
\hline 17 & $\mathrm{M}$ & 26 & 9 & 145/50/T7 & $S$ & 160/60/T7 & 45 & 49 \\
\hline 18 & $\mathrm{M}$ & 23 & 15 & 170/70/T7 & $S$ & 160/40/T12 & 100 & 37 \\
\hline 19 & $\mathrm{M}$ & 30 & 15 & 160/30/T10 & $S$ & 170/80/T8 & 100 & 35 \\
\hline 20 & $\mathrm{M}$ & 49 & 6 & 150/55/T10 & $S$ & 130/40/T7 & 100 & 24 \\
\hline 21 & $\mathrm{M}$ & 38 & 8 & 110/20/L3 & $S$ & 120/40/T8 & 80 & 24 \\
\hline 22 & $\mathrm{~F}$ & 29 & 10 & 160/60/T9 & $S$ & 170/80/T10 & 40 & 24 \\
\hline 23 & $\mathrm{M}$ & 45 & 8 & 160/60/T6 & $\mathrm{S}$ & 170/60/T5 & 100 & 24 \\
\hline 24 & $M$ & 17 & 3 & 150/40/T7 & $S$ & 160/80/T7 & 100 & 40 \\
\hline 25 & $\mathrm{~F}$ & 17 & 3 & 140/40/T9 & $S$ & 160/80/T7 & 100 & 36 \\
\hline 26 & $\mathrm{~F}$ & 28 & 3 & 140/50/T8 & $S$ & 160/80/T7 & 100 & 25 \\
\hline 27 & $\mathrm{~F}$ & 22 & 3 & 160/60/T7 & $S$ & 160/70/T7 & 100 & 25 \\
\hline
\end{tabular}




\section{DISCUSSION}

The standard procedure for treating post-traumatic anterior shoulder instability is Bankart lesion repair, with reinsertion of the anteroinferior labrum in the anterior glenoid rim or in the neck of the scapula $^{(10)}$. Studies conducted more recently have rejected suturing of the lesion at the neck of the scapula and have recommended suturing at the glenoid rim, along a length of 2 to $3 \mathrm{~mm}$ on the anterior internal glenoid rim, in the belief that the barrier created through labral and capsular reinsertion might help to stabilize the shoulder, thereby functioning as a mechanical barrier ${ }^{(17)}$.

Burkhart et $\mathrm{al}^{(18)}$ described a technique for opening the anterior joint margin of the glenoid cavity and exposing the subchondral bone, with capsule-ligament fixation using bioabsorbable anchors in this bed, which they believed would lead to better healing of the lesion. We share this opinion, since healing over the joint cartilage could be one of the contributory reasons for recurrence of dislocations.

Recent studies have demonstrated that the results from treatment with arthroscopic viewing are comparable with those from an open approach, with the advantage of providing better postoperative comfort for the patients and the possibility of making an inventory of the joint cavity to seek diagnoses and treatments for associated lesions ${ }^{(15,16,20)}$, which was done frequently among our patients.

From a review of the literature, Mohtadi et $\mathrm{al}^{(21)}$ demonstrated a recurrence rate of $10 \%$ when anchors were used under arthroscopic viewing. Barber et $\mathrm{al}^{(22)}$ reported recurrence of $7 \%$ from using bioabsorbable anchors in 57 patients. From a meta-analysis, Hobby et al ${ }^{(16)}$ described a mean recurrence rate of $8.9 \%$. In our setting, Godinho et $\mathrm{al}^{(12)}$ presented results from arthroscopic surgical treatment after two years of follow-up with a recurrence rate of $8.9 \%$. We found a recurrence rate of $7 \%$ after two years of follow-up, which is comparable with the best rates found in the literature.

Among our patients who suffered recurrence of instability, one was a professional Greco-Roman wrestler who went back to his sport without any symptoms of instability, but then presented a new episode of traumatic dislocation during a competition, after two years of postoperative follow-up. From reviewing the literature, we noted that there was a hi- gher recurrence rate among people practicing contact sports, like the abovementioned case, and that the rate could range from $15 \%$ to $25 \%{ }^{(23)}$. In the index described by Boileau, young patients practicing sports at a high level had better results when the treatment was done as open surgery ${ }^{(24)}$, which has led us to think again regarding indications for arthroscopic treatment among patients with this profile. The other of our patients who presented recurrence of instability suffered an episode of dislocation after one and a half years of follow-up, also with traumatic etiology.

Two patients continued to complain of pain in the operated shoulder: one case with pain during intense physical activity practice and the other with pain even at rest. These two cases are still undergoing diagnostic investigation, without coming to any conclusion so far, because they do not present any signs of instability on physical examination, or any abnormality suggestive of joint lesions on magnetic resonance imaging that would explain the pain.

There was an improvement in the range of motion in relation to the preoperative situation, albeit without statistical significance, consisting of seven degrees of elevation, 10 degrees of lateral rotation and one vertebral level of medial rotation. These findings differed from the results presented by Mazzocca et al ${ }^{(23)}$, who demonstrated that there was a slight decrease in lateral rotation after the operation, in contact sport players.

According to the Rowe scale, Fabbriciani et al ${ }^{(20)}$ obtained a mean score of 91 points for cases of instability that were treated with arthroscopic viewing, Barber et $\mathrm{al}^{(22)}$ found a mean of 93 points, with a range from 40 to 100 points, and Kim et $\mathrm{al}^{(11)}$ found that $95 \%$ of the results were satisfactory. In our setting, Godinho et al ${ }^{(12)}$ obtained a mean of 92 points, with a range from 25 to 100 points. In the same way, the mean result presented by our patients was 95 points, with a range from 45 to 100 points, which is comparable with the best results found in the literature, with excellent results in $93 \%$ of the cases and poor results in $7 \%$.

\section{CONCLUSION}

The treatment for traumatic anterior shoulder instability using the technique of opening the anterior joint margin of the glenoid cavity (glenoid rim), to repair the Bankart lesion, provided excellent results for $93 \%$ of the patients operated. 


\section{REFERENCES}

1. Gartsman GM, Roddey TS, Hammerman SM. Arthroscopic treatment of anterior-inferior glenohumeral instability. Two to five-year follow-up. J Bone Joint Surg Am. 2000;82(7):991-1003.

2. Jakobsen BW, Johannsen HV, Suder P, Søjbjerg JO. Primary repair versus conservative treatment of first-time traumatic anterior dislocation of the shoulder: a randomized study with 10-year follow-up. Arthroscopy. 2007;23(2):118-23.

3. Bigliani LU, Kurzweil PR, Schwartzbach CC, Wolfe IN, Flatow EL. Inferior capsular shift procedure for anterior-inferior shoulder instability in athletes. Am J Sports Med. 1994;22(5):578-84.

4. Bankart $A$. The pathology and treatment of recurrent dislocation of the shoulder joint. Br J Surg 1938;26(1):23-9.

5. Rowe CR, Patel D, Southmayd WW. The Bankart procedure: a long-term end-result study. J Bone Joint Surg Am. 1978;60(1):1-16.

6. Karlsson J, Magnusson L, Ejerhed L, Hultenheim I, Lundin O, Kartus J. Comparison of open and arthroscopic stabilization for recurrent shoulder dislocation in patients with a Bankart lesion. Am J Sports Med. 2001;29(5):538-42.

7. Snyder SJ. Shoulder instability. In: Shoulder arthroscopy. New York: McGraw-Hill; 1994. p. 179-213.

8. Johnson LL. Shoulder arthroscopy. In: Arthroscopic surgery: principals and practice. 3rd. St Louis: CV Mosby; 1986. p. 398-412.

9. Morgan $C D$, Bodenstab AB. Arthroscopic Bankart suture repair: technique and early results. Arthroscopy. 1987;3(2):111-22.

10. Wolf EM. Arthroscopic capsulolabral repair using suture anchors. Orthop Clin North Am. 1993;24(1):59-69.

11. Kim SH, Ha KI, Cho YB, Ryu BD, Oh I. Arthroscopic anterior stabilization of the shoulder: two to six-year follow-up. J Bone Joint Surg Am. 2003;85(8):1511-8.

12. Godinho GG, França FO, Freitas JMA, Menezes CM, Freire SG, Wanderley AL, et al. Tratamento artroscópico da instabilidade anterior traumática do ombro: resultados a longo prazo e fatores de risco. Rev Bras Ortop. 2008;43(5):157-66.

13. Ozbaydar M, Elhassan B, Diller D, Massimini D, Higgins LD, Warner JJ. Results of arthroscopic capsulolabral repair: Bankart lesion versus anterior labroligamentous periosteal sleeve avulsion lesion. Arthroscopy. 2008;24(11):1277-83.
14. Hantes ME, Venouziou AI, Liantsis AK, Dailiana ZH, Malizos KN. Arthroscopic repair for chronic anterior shoulder instability: a comparative study between patients with Bankart lesions and patients with combined Bankart and superior labral anterior posterior lesions. Am J Sports Med. 2009;37(6):1093-8.

15. Bottoni CR, Smith EL, Berkowitz MJ, Towle RB, Moore JH. Arthroscopic versus open shoulder stabilization for recurrent anterior instability: a prospective randomized clinical trial. Am J Sports Med. 2006;34(11):1730-7.

16. Hobby J, Griffin D, Dunbar M, Boileau P. Is arthroscopic surgery for stabilisation of chronic shoulder instability as effective as open surgery? A systematic review and meta-analysis of 62 studies including 3044 arthroscopic operations. J Bone Joint Surg Br. 2007;89(9):1188-96.

17. Itoi E, Cofield RH, Steinmann SP. Does the "bumper" created during Bankart repair contribute to shoulder stability? In: 11th International Congress of Shoulder and Elbow Surgery, Edinburgh, 2010.

18. Burkhart SS, Lo IKY, Brady PC. "Instability: arthroscopy Barkart repair". In: Burkhart"s view of the shoulder: a cowboy"s guide to advanced shoulder arthroscopy. Philadelphia: Lippincott Williams e Wilkins; 2006. p. 217-20.

19. American Academy of Orthopeadic Surgeons; Joint motion: method of measuring and recording. Chicago, AAOS meeting, 1965. p. 10-43

20. Fabbriciani C, Milano G, Demontis A, Fadda S, Ziranu F, Mulas PD. Arthroscopic versus open treatment of Bankart lesion of the shoulder: a prospective randomized study. Arthroscopy. 2004;20(5):456-62.

21. Mohtadi NG, Bitar IJ, Sasyniuk TM, Hollinshead RM, Harper WP. Arthroscopic versus open repair for traumatic anterior shoulder instability: a meta-analysis. Arthroscopy. 2005;21(6):652-8.

22. Barber FA, Snyder SJ, Abrams JS, Fanelli GC, Savoie FH 3rd. Arthroscopic Bankart reconstruction with a bioabsorbable anchor. J Shoulder Elbow Surg. 2003;12(6):535-8.

23. Mazzocca AD, Brown FM Jr, Carreira DS, Hayden J, Romeo AA. Arthroscopic anterior shoulder stabilization of collision and contact athletes. Am J Sports Med. 2005;33(1):52-60.

24. Balg F, Boileau P. The instability severity index score. A simple pre-operative score to select patients for arthroscopic or open shoulder stabilisation. J Bone Joint Surg Br. 2007;89(11):1470-7. 